\title{
Peroxynitrite Donor SIN-1 Alters High-Affinity Choline Transporter Activity by Modifying Its Intracellular Trafficking
}

\author{
Leah K. Cuddy, ${ }^{1}$ Alexis C. Gordon, ${ }^{2}$ Stefanie A. G. Black, ${ }^{3}$ Ewa Jaworski, ${ }^{1}$ Stephen S. G. Ferguson, ${ }^{1}$ and R. Jane Rylett ${ }^{1}$ \\ ${ }^{1}$ Molecular Brain Research Group, Robarts Research Institute, London, Ontario N6A 5K8, Canada, and Department of Physiology and Pharmacology, \\ Schulich School of Medicine and Dentistry, University of Western Ontario, London, Ontario N6A 5C1, Canada, ${ }^{2}$ University of Toronto, Toronto, Ontario \\ M5S 1A1, Canada, and ${ }^{3}$ Hotchkiss Brain Institute, University of Calgary, Calgary, Alberta T2N 4N1, Canada
}

Sodium-coupled, high-affinity choline transporters (CHTs) are inhibited by 3-morpholinosydnonimine (SIN-1) [peroxynitrite $\left(0 \mathrm{ONO0}{ }^{-}\right.$) donor]; $\mathrm{ONOO}^{-}$can be produced from nitric oxide and reactive oxygen species during neurodegeneration. SIN-1 rapidly increases $\mathrm{CHT}$ internalization from the cell surface, and this correlates with decreased choline uptake. This study addresses mechanisms by which SIN-1 inhibits CHT function in human neuronal SH-SY5Y cells. Thus, mutant L531A-CHT, which does not constitutively internalize into cells by a clathrin-mediated process, is resistant to SIN-1 effects. This suggests that CHT inhibition is not due to oxidative-nitrosative inactivation of the protein and that decreased levels of cell surface CHT in SIN-1-treated cells is related to alterations in its trafficking and subcellular disposition. Dominant-negative proteins AP180C and dynamin-K44A, which interfere with clathrin-mediated and dynamindependent endocytosis, respectively, attenuate CHT inhibition by SIN-1. CHT in both vehicle- and SIN-1-treated cells colocalizes with Rab7, Rab9, and Lamp-1 in late endosomes and lysosomes to a similar extent. Lysosome inhibitors increase choline uptake, suggesting that CHT proteins are normally degraded by lysosomes, and this is not altered by oxidative stress. Unexpectedly, inhibitors of proteasomes, but not lysosomes, attenuate SIN-1-mediated inhibition of choline uptake, indicating that proteasomal degradation plays a role in regulating CHT disposition in SIN-1-treated cells. SIN-1 treatment also enhances CHT ubiquitination. Thus, CHT inhibition in SIN-1treated cells is mediated by proteasomal degradation, which differs from inhibitory mechanisms for some neurotransmitter transporters under similar conditions. Increased oxidative-nitrosative stress in the microenvironment of cholinergic nerve terminals would diminish cholinergic transmission by reducing choline availability for ACh synthesis.

\section{Introduction}

The sodium-coupled, high-affinity choline transporter (CHT) is an integral component of cholinergic neurons that moves choline from the synaptic cleft into cholinergic nerve endings where it is used as substrate for acetylcholine (ACh) synthesis. This choline uptake is hemicholinium-3 (HC-3) sensitive and can be the rate-limiting step for ACh synthesis (Haga and Noda, 1973; Yamamura and Snyder, 1973). Importantly, CHT is sensitive to oxidative stress (Guermonprez et al., 2001; Pinthong et al., 2008) and thus a critical target for disruption of cholinergic neuronal communication.

Received Oct. 17, 2011; revised Feb. 24, 2012; accepted March 4, 2012.

Author contributions: R.J.R. designed research; L.K.C., A.C.G., S.A.G.B., and E.J. performed research; S.S.G.F. contributed unpublished reagents/analytic tools; L.K.C., A.C.G., S.A.G.B., E.J., and R.J.R. analyzed data; L.K.C., A.C.G., S.A.G.B., and R.J.R. wrote the paper.

This work was supported by operating grants from the Canadian Institutes for Health Research (CIHR) and the Alzheimer Society of Canada (R.J.R.). L.K.C. is the recipient of a Graduate Student Training Award from the Alzheimer Society London-Middlesex Chapter, A.C.G. is the recipient of an Ontario Graduate Scholarship, S.A.G.B. is the recipient of a Doctoral Research Award from CIHR, and S.S.G.F. is a Career Investigator of the Heart and Stroke Foundation of Ontario and holds the Tier I Canada Research Chair in Molecular Neurobiology.

Correspondence should be addressed to Dr. Rebecca Jane Rylett, Molecular Brain Research Group, Robarts Research Institute, 100 Perth Drive, London, 0N N6A 5K8, Canada. E-mail: jane.rylett@schulich.uwo.ca.

DOI:10.1523/JNEUROSCI.5235-11.2012

Copyright $\odot 2012$ the authors $\quad 0270-6474 / 12 / 325573-12 \$ 15.00 / 0$
Increasing evidence suggests a role for reactive oxygen and nitrogen moieties in progression of neurodegenerative disorders such as Alzheimer's disease (Wang and Michaelis, 2010). Peroxynitrite $\left(\mathrm{ONOO}^{-}\right)$forms by combination of superoxide $\left(\mathrm{O}_{2}^{-}\right)$and nitric oxide (NO), with these reactive species occurring in response to tissue injury (Beckman, 1991, 1994; Smith et al., 1997; Xu et al., 2001; Alkam et al., 2007). ONOO ${ }^{-}$has multiple fates within cells, including contributing to membrane lipid peroxidation and protein oxidation and nitration. $\mathrm{ONOO}^{-}$inhibits the function of some neurotransmitter transporters, including the human dopamine (hDAT) (Park et al., 2002) and 5-hydroxytryptamine (hSERT) transporters (Bryan-Lluka et al., 2004). Also, $\mathrm{ONOO}^{-}$decreases CHT activity in Torpedo marmorata synaptosomes (Guermonprez et al., 2001). Our laboratory found that 3-morpholinosydnonimine (SIN-1), which generates $\mathrm{ONOO}^{-}$and other reactive oxidants, causes rapid, dose-dependent inhibition of CHT and this is attenuated by $\mathrm{ONOO}^{-}$scavengers (Pinthong et al., 2008). Importantly, $\mathrm{H}_{2} \mathrm{O}_{2}$ did not alter CHT activity (Guermonprez et al., 2001; Pinthong et al., 2008).

CHT proteins internalize constitutively by clathrin-mediated endocytosis, residing predominantly in intracellular organelles including synaptic vesicles rather than being at the cell surface (Ferguson et al., 2003; Ribeiro et al., 2003, 2005, 2006, 2007; 
Ferguson and Blakely, 2004). Recruitment of CHT to the plasma membrane is a critical mechanism regulating solute transport (Apparsundaram et al., 2000; Okuda and Haga, 2000; Ferguson et al., 2003; Ribeiro et al., 2006). CHT interaction with endocytic machinery is mediated by a dileucine-like motif located in its intracellular $\mathrm{C}$ terminus, and we showed that mutation of a single leucine in this motif (L531A) substantially reduces constitutive trafficking of CHT with L531A-CHT proteins retained at the cell surface (Ribeiro et al., 2005).

We found that inhibition of choline uptake in SIN-1-treated cells is due to decreased cell surface CHT levels rather than to altered solute binding affinity, and that SIN-1 modulates CHT activity by increasing its internalization and this correlates with decreased plasma membrane CHT (Pinthong et al., 2008). However, the mechanisms by which SIN-1 modulates CHT trafficking between plasma membrane and subcellular organelles are unknown. Thus, the aim of this study was to characterize mechanisms by which SIN-1 modulates CHT function. The endocytosisdefective mutant L531A-CHT was used to test our prediction that it would be resistant to SIN-1 inhibition if the mechanism by which SIN-1 decreases CHT activity involves enhancing CHT internalization. We tracked CHT movement in endosomal-lysosomal compartments and found that acute SIN-1 treatment does not alter these events, but importantly blocking proteasome, but not lysosome, function attenuated SIN-1-mediated inhibition of CHT.

\section{Materials and Methods}

Materials. SIN-1 was from BIOMOL Research Laboratories, lactacystin and $\mathrm{N}$-(benzyloxycarbonyl)leucinylleucinylleucinal (MG-132) were from Calbiochem, chloroquine, anti-FLAG M2 affinity gel, mouse IgGagarose, and rabbit polyclonal anti-FLAG antibody were from SigmaAldrich, bafilomycin A1 and mouse monoclonal anti-ubiquitin antibody (P4D1) were from Santa Cruz Biotechnology, and $\left[\right.$ methyl $\left.-{ }^{3} \mathrm{H}\right]$ choline chloride $(128 \mathrm{Ci} / \mathrm{mmol})$ and $\left[\right.$ methyl $\left.{ }^{3} \mathrm{H}\right]$ hemicholinium-3 diacetate $\left(\left[{ }^{3} \mathrm{H}\right] \mathrm{HC}-3\right)(144.5 \mathrm{Ci} / \mathrm{mmol})$ were from PerkinElmer Life Sciences. Other chemicals were purchased from Sigma-Aldrich at the highest purity available. SH-SY5Y human neuroblastoma cells were from the American Type Culture Collection, and Invitrogen supplied HEK 293 Flp-In cells, fetal bovine serum (FBS), Lipofectamine 2000, OptiMEM, and culture media and reagents. Zenon-Alexa Fluor 488 and 555 mouse IgG labeling kits were from Invitrogen. Enhanced ChemiLuminescence immunoblot reagent (ECL) was from GE Healthcare Life Sciences and Biodegradable Scintillant was from GE Healthcare. Polyclonal CHT antibody was raised in rabbits to the antigenic peptide DVDSSPEGSGTEDNLQ, which is conserved at the $\mathrm{C}$ terminus of human and rat CHT (Genemed Synthesis); this peptide was conjugated to KLH carrier protein by an $\mathrm{N}$-terminal cysteine residue. CHT-specific IgG was affinity-purified in our laboratory from the crude antiserum on NHS-Sepharose (GE Healthcare) to which antigenic peptide had been coupled as the binding element. The specificity of this antibody for detection of CHT was described previously (Pinthong et al., 2008). Peroxidase-conjugated goat anti-rabbit IgG was from Jackson ImmunoResearch Laboratories.

Cell transfection and selection of cell lines. Full-length rat CHT cDNA ligated to pSPORT was a gift from Dr. T. Okuda (Okuda et al., 2000); a FLAG epitope tag (DYKDDDDK) was added to the $\mathrm{N}$ terminus by PCR and the resulting cDNA ligated to pcDNA3.1 or pcDNA5 (Pinthong et al., 2008). Mutant L531A-CHT was produced by site-directed mutagenesis using QuikChange kit (Stratagene). SH-SY5Y cells were transfected with plasmids (FLAG-CHT or FLAG-L531A-CHT cDNA ligated to pcDNA3.1) by Lipofectamine 2000. Stable transformants (SY5Y-CHT and SY5Y-L531A-CHT, respectively) were selected using $500 \mu \mathrm{g} / \mathrm{ml}$ geneticin (G418) for 4 weeks, and then grown in DMEM, 10\% FBS, 100 $\mathrm{U} / \mathrm{ml}$ penicillin, and $100 \mu \mathrm{g} / \mathrm{ml}$ each of streptomycin and G418. SHSY5Y cell differentiation was induced by the addition of $10 \mu \mathrm{M}$ RA (alltrans-retinoic acid) for $3 \mathrm{~d}$; substantial morphological and biochemical differentiation of cells occurred during this time frame. HEK 293 cell lines stably expressing FLAG-CHT were created by introducing the cDNA ligated to pcDNA5 into the FRT (Flp recombinase target) site in HEK-Flp-In cells by Lipofectamine 2000 transfection (HEK-CHT cells). Stable transformants were selected and expanded in DMEM containing $10 \% \mathrm{FBS}, 10 \mu \mathrm{g} / \mathrm{ml}$ gentamicin, and $50 \mu \mathrm{g} / \mathrm{ml}$ hygromycin-B.

For transient transfection, cells were plated and treated with retinoic acid for $2 \mathrm{~d}$ before transfection, and immediately before transfection the culture medium was changed to complete medium that did not contain antibiotics. At the time of transfection, $1 \mu \mathrm{g}$ of plasmid DNA in $100 \mu \mathrm{l}$ of OptiMEM was added to $100 \mu \mathrm{l}$ of OptiMEM containing $2.5 \mu \mathrm{l}$ of Lipofectamine 2000, and then incubated for $20 \mathrm{~min}$ at room temperature. This mixture was added to monolayers of cells in antibiotic-free medium and incubated for $6 \mathrm{~h}$. At the end of the incubation with transfection reagents, culture medium was replaced with complete medium containing retinoic acid, and cells were then grown for an additional $24 \mathrm{~h}$.

To inhibit clathrin-mediated constitutive trafficking of $\mathrm{CHT}$ proteins, we used AP180C, a dominant-negative (DN) protein of the C-terminal portion of adaptin AP180, which can bind to and sequester clathrin to effectively interfere with clathrin-mediated endocytosis (Ford et al., 2001). Interruption of dynamin-mediated protein trafficking was achieved using Dyn-K44A as a DN dynamin protein, which has a point mutation that ablates the dynamin GTPase activity that is required for membrane scission (Damke et al., 2001). SY5Y-CHT cells were transiently transfected to enable expression of these dominant-negative proteins using $5 \mu \mathrm{g}$ of AP180C or Dyn-K44A plasmid DNA per $35 \mathrm{~mm}$ plate; transfection efficiency was $\sim 35 \%$. To assess CHT localization to early and late endosomes, cells were transiently transfected with subcellular compartment markers Rab5a-GFP (early endosomes), Rab7-GFP (early to late endosomes), and Rab9-YFP (late endosomes) using 2, 1, and 0.5 $\mu \mathrm{g}$ of plasmid DNA per $35 \mathrm{~mm}$ dish, respectively. Transfection efficiency observed for these fluorescently tagged proteins was $\sim 20 \%$.

SIN-1 treatment. The use of $\mathrm{ONOO}^{-}$donors such as SIN-1 allows continuous production of a low level of $\mathrm{ONOO}^{-}$by a substance that is relatively stable over a longer period of time (Pacher et al., 2007). As the half-life of $\mathrm{ONOO}^{-}$radical is $<1 \mathrm{~s}$, bolus administration of this agent does not produce either consistent or sustained concentrations of $\mathrm{ONOO}^{-}$under experimental conditions. The donor efficiency of SIN-1 may be altered by changes in $\mathrm{pH}$ or buffer composition; previous studies that used a Krebs' buffer similar to the one used in the present study estimated that $1 \mu \mathrm{mol}$ of $\mathrm{ONOO}^{-}$is formed per minute in a solution of $1 \mathrm{~mm}$ SIN-1. This suggests that the SIN-1 treatments used here could generate $\mathrm{ONOO}^{-}$levels representative of that seen in brain under some conditions (Ashki et al., 2008). The estimated half-life for SIN-1 in these buffer conditions is 14-26 min, suggesting that donor activity would be sustained throughout the treatment periods used in our study. Total $\mathrm{ONOO}^{-}$production capacity under these buffer conditions has been estimated to be $30 \mu \mathrm{m}$, although the $\mathrm{ONOO}^{-}$concentration in solution at a given time will be lower than this due to its much shorter half-life.

Confocal cell imaging. Digital images of live and fixed cells were acquired with a Zeiss LSM510-Meta laser-scanning confocal microscope using a $63 \times$ magnification oil-immersion objective. Fluorescent labeling of FLAG-tagged CHT proteins in live cells was accomplished using rabbit anti-FLAG antibody complexed to either Zenon 555 dye (for Rab5aGFP, Rab7-GFP, and Rab9-YFP) or Zenon 488 dye (for Lamp-1 staining or when no costain was used). This fluorescently tagged antibody was added to the medium bathing cells where it could bind to the FLAG epitope on the extracellularly oriented $\mathrm{N}$ terminus of CHT proteins inserted at the plasma membrane. Imaging of live cells allowed real-time tracking of internalization of CHT into cells and movement of these proteins between subcellular organelles. In some experiments, cells were transiently transfected to allow expression of the fluorescently labeled subcellular compartment markers Rab5a-GFP, Rab7-GFP, or Rab9-YFP. Also, in some experiments, cells were formaldehyde fixed after allowing the internalization of Zenon-labeled CHT proteins, as this facilitated imaging and was required for counterstaining cells to visualize lysosomes using an anti-human antibody directed to LAMP-1. Formalin fixation of GFP or YFP-fusion protein-expressing cells did not alter the image qual- 
ity of these fluorophores compared with images that were captured from live cells expressing these fusion proteins.

Colocalization analysis was performed on confocal images using Imaris 7.0 with the Imaris Colocalization module (bit-plane) to examine the colocalization of the brightest $2 \%$ of pixels in each channel, as described previously (Lorenzen et al., 2010). Graphing and statistical analysis of the data were performed with GraphPad Prism and Instat using one-way ANOVA with Tukey's post hoc test.

$\left[{ }^{3} \mathrm{H}\right]$ Choline uptake assay. Monolayers of cells were washed, and then incubated at $37^{\circ} \mathrm{C}$ in Krebs'-Ringer's-HEPES solution (KRH) (in mM: $124 \mathrm{NaCl}, 5 \mathrm{KCl}, 1.3 \mathrm{MgSO}_{4}, 1.5 \mathrm{CaCl}_{2}, 10$ glucose, 20 HEPES-NaOH, $\mathrm{pH}$ 7.4). Either vehicle or SIN-1 was added to cells for specified times, followed by incubation for $5 \mathrm{~min}$ with $0.5 \mu \mathrm{M}\left[{ }^{3} \mathrm{H}\right]$ choline $(0.5 \mu \mathrm{Ci} / \mathrm{ml})$ in the absence or presence of $1 \mu \mathrm{M}$ HC-3. Cells were placed on ice and washed with cold $\mathrm{KRH}$, and then lysed in $0.1 \mathrm{M} \mathrm{NaOH}$. After $30 \mathrm{~min}$ incubation, aliquots of samples were analyzed for tritium by liquid scintillation spectrometry and protein concentration using Bio-Rad protein dye. Each independent experiment consisted of triplicate plates of cells per treatment group, with results normalized to sample protein content and averaged. Specific choline uptake was calculated as the difference between total choline uptake and nonspecific uptake in the presence of HC-3, with the resulting $\left[{ }^{3} \mathrm{H}\right]$ choline uptake data expressed as picomoles/milligram of protein per 5 min \pm SEM.

$\left[{ }^{3} \mathrm{H}\right] \mathrm{HC}-3$ binding assay. Monolayers of cells were washed and incubated in $\mathrm{KRH}$ at $37^{\circ} \mathrm{C}$ with the addition of either vehicle or $1 \mathrm{~mm} \mathrm{SIN-1}$ for specified times, and then washed with ice-cold KRH and kept on ice for $10 \mathrm{~min}$ to stop protein trafficking activity. Cells were then incubated with $\left[{ }^{3} \mathrm{H}\right] \mathrm{HC}-3(10 \mathrm{~nm} ; 0.23 \mathrm{Ci} / \mathrm{mmol})$ in the presence or absence of 1 $\mu \mathrm{M}$ unlabeled $\mathrm{HC}-3$ for $1 \mathrm{~h}$ on ice. For kinetic analysis, HC-3 binding was measured over the range of $0.5-10 \mathrm{nM} \mathrm{HC}-3$ with the specific activity of $\left[{ }^{3} \mathrm{H}\right] \mathrm{HC}-3$ held constant at $0.23 \mathrm{Ci} / \mathrm{mmol}$. Following incubation, cells were washed rapidly with cold $\mathrm{KRH}$ to remove unbound $\mathrm{HC}-3$ and then lysed using $0.1 \mathrm{M} \mathrm{NaOH}$ for $30 \mathrm{~min}$. Aliquots of cell lysates were used for quantification of tritium and protein content. Each independent experiment had triplicate determinations with HC-3 binding normalized to sample protein content and then averaged. Specific HC-3 binding was calculated as the difference between total and nonspecific $\mathrm{HC}-3$ binding, and values were expressed as femtomoles/milligram of protein \pm SEM.

Cell surface protein biotinylation assay. Cells plated on $60 \mathrm{~mm}$ dishes were washed with HEPES-buffered saline solution (HBSS), and then treated at $37^{\circ} \mathrm{C}$ with either vehicle (HBSS) or HBSS containing $1 \mathrm{~mm}$ SIN-1 for the times indicated. After treatment, cells were placed on ice under cold HBSS to stop protein trafficking. Plasma membrane proteins were biotinylated on ice by incubating with $1 \mathrm{mg} / \mathrm{ml}$ sulfo-NHS-SSbiotin in HBSS for $1 \mathrm{~h}$ (Dale et al., 2004; Pinthong et al., 2008). Unbound biotin was quenched by washing and incubating cells in cold $100 \mathrm{~mm}$ glycine in HBSS. After two further washes with HBSS, cells were lysed on ice for $30 \mathrm{~min}$ in $1 \%$ Triton X-100 lysis buffer $(1 \% \mathrm{w} / \mathrm{v}$ Triton $\mathrm{X}-100,150 \mathrm{~mm} \mathrm{NaCl}, 50 \mathrm{~mm}$ Tris-HCl, pH 7.5, 1 mм AEBSF [4-(2aminoethyl)benzenesulfonyl fluoride], $10 \mu \mathrm{g} / \mathrm{ml}$ each of leupeptin and aprotinin, and $25 \mu \mathrm{g} / \mathrm{ml}$ pepstatin $\mathrm{A}, 700 \mathrm{U} / \mathrm{ml}$ DNase). Neutravidin beads were incubated with cell lysates for $1 \mathrm{~h}$ at $4^{\circ} \mathrm{C}$ with gentle mixing to bind biotin-labeled proteins to allow separation from the nonbiotinylated proteins. Beads were then washed with lysis buffer three times, PBS twice, and bound proteins were eluted by incubation for $10 \mathrm{~min}$ at $55^{\circ} \mathrm{C}$ with Laemmli sample buffer (2\% SDS, $10 \%$ glycerol, $62.5 \mathrm{~mm}$ Tris- $\mathrm{HCl}$, pH 6.8, 2.5\% $\beta$-mercaptoethanol, and $0.001 \%$ bromophenol blue). Aliquots of biotinylated proteins and total cell lysates were separated on $7.5 \%$ SDS-PAGE gels and transferred to polyvinylidene difluoride (PVDF) membranes. Membranes were blocked in $8 \%$ nonfat dry milk in wash buffer (PBS, $0.1 \%$ Tween 20) for $1 \mathrm{~h}$, and then incubated for $2 \mathrm{~h}$ with rabbit anti-CHT antibody (1:1000) in wash buffer with $8 \%$ milk. After washing, membranes were incubated for $1 \mathrm{~h}$ with peroxidaseconjugated goat anti-rabbit IgG secondary antibody $(1: 10,000)$ in wash buffer containing $8 \%$ milk, and washed again. Immunoreactive proteins on membranes were detected by chemiluminescence using the ECL kit. Immunopositive bands (at $\sim 50 \mathrm{kDa}$ for $\mathrm{CHT}$ protein) were quantified by densitometry using Scion Image software (NIH). Bands for cell sur- face $\mathrm{CHT}$ were normalized by comparison to vehicle-treated control cells in each experiment, which represented the basal cell surface CHT levels.

Protein ubiquitination assay. SY5Y-CHT cells or SH-SY5Y cells stably expressing pcDNA3.1 empty vector plated on $100 \mathrm{~mm}$ dishes were washed with $\mathrm{HBSS}$, and then treated at $37^{\circ} \mathrm{C}$ with either vehicle (HBSS) or HBSS containing $1 \mathrm{~mm} \mathrm{SIN-1}$ for $20 \mathrm{~min}$. After two washes with cold HBSS, cells were lysed at $4^{\circ} \mathrm{C}$ for $30 \mathrm{~min}$ in $0.25 \%$ Triton X-100 lysis buffer. Following centrifugation at $12,000 \times g$ for $10 \mathrm{~min}$, supernatants were transferred to fresh tubes. Aliquots of cell lysates containing $500 \mu \mathrm{g}$ of protein were precleared for $60 \mathrm{~min}$ with $50 \mu \mathrm{l}$ of mouse IgG-agarose, and then incubated for $90 \mathrm{~min}$ with $50 \mu \mathrm{l}$ of washed anti-FLAG M2 affinity resin. Anti-FLAG affinity resin with bound proteins was collected by centrifugation and washed three times with lysis buffer to remove nonspecific proteins. Proteins were eluted by incubation for $10 \mathrm{~min}$ at $55^{\circ} \mathrm{C}$ with Laemmli sample buffer, and then separated on $7.5 \%$ SDSPAGE gels and transferred to PVDF membranes. Membranes were blocked in $8 \%$ nonfat dry milk in wash buffer for $1 \mathrm{~h}$, and then incubated overnight at $4^{\circ} \mathrm{C}$ with anti-CHT antibody or anti-ubiquitin antibody. After washing, membranes were incubated for $1 \mathrm{~h}$ in wash buffer containing $8 \%$ milk and either peroxidase-conjugated goat anti-rabbit IgG secondary antibody or peroxidase-conjugated goat anti-mouse IgG secondary antibody. Immunoreactive proteins on membranes were detected by chemiluminescence. Membranes were stripped for $20 \mathrm{~min}$ at $55^{\circ} \mathrm{C}$ followed by $5 \mathrm{~min}$ at room temperature in stripping buffer $(62.5 \mathrm{~mm}$ Tris-HCl, pH 6.7, 2\% SDS, 0.78\% 2-mercaptoethanol), and then washed five times for $30 \mathrm{~min}$ in wash buffer before being reprobed with a different primary antibody.

Data analysis. Data are presented as the mean \pm SEM with $n$ values representing the number of independent experiments performed on separate populations of cells; each $n$ value was obtained from the average of multiple sample replicates in each experiment. Replicate experiments were performed on cells cultured in successive passages as much as possible to minimize interexperiment variability; intraexperiment variability between replicate samples was minimal, thus facilitating comparisons of treatment effects. GraphPad Prism 5 and InStat software were used for data analysis. Sigmoid and Michaelis-Menten equations were used to calculate kinetic parameters $\left(B_{\max }\right.$ and $K_{\mathrm{D}}$ ) of HC-3 binding. Data were assessed for statistically significant differences by paired Student's $t$ test, or between groups using one-way ANOVA with either Dunnett's or Tukey's post hoc multiple-comparison test, as appropriate.

\section{Results}

\section{SIN-1 decreases activity of wild-type CHT, but not mutant L531A-CHT}

Initial experiments in the present study characterized SIN-1 effects on choline uptake in SH-SY5Y cells stably expressing wildtype CHT or the endocytosis-deficient mutant L531A-CHT. We showed previously that SIN-1 treatment of cells decreases choline uptake activity and reduces cell surface $\mathrm{CHT}$ levels due to accelerated endocytosis (Pinthong et al., 2008). Also, CHT undergoes clathrin-mediated endocytosis, and L531A-CHT, which lacks the dileucine trafficking motif, is defective in this internalization (Ribeiro et al., 2005). Thus, we predicted that if SIN-1 reduces cell surface levels of CHT by increasing its clathrin-mediated endocytosis, then L531A-CHT activity would be resistant to this SIN1-mediated effect.

Laser-scanning confocal images of live cells confirmed that a large proportion of CHT is located in subcellular organelles, whereas L531A-CHT resides at the cell surface (data not shown) (Ribeiro et al., 2005). Also, consistent with the increased levels of plasma membrane CHT, choline uptake activity in SY5Y-L531ACHT cells is significantly greater than in SY5Y-CHT cells (1673 \pm 151 and $816 \pm 106 \mathrm{pmol} / \mathrm{mg}$ protein per $5 \mathrm{~min}$, respectively). A critical observation made in the present study in support of our prediction is that acute SIN-1 exposure caused a dose-dependent decrease in choline uptake by wild-type CHT but did not alter 


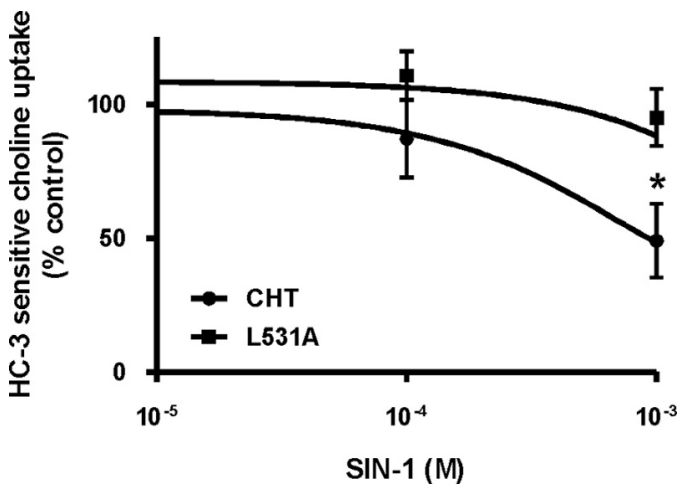

Figure 1. SIN-1 inhibits choline uptake activity of wild-type CHT but not L531A-CHT in SHSY5Y cells. Retinoic acid-differentiated SH-SY5Y cells stably expressing either wild-type CHT or L531A-CHT were treated for $30 \mathrm{~min}$ with either vehicle or varying concentrations of SIN-1, and then HC-3-sensitive choline uptake activity was measured. Baseline uptake was found to be $816 \pm 106$ and $1673 \pm 151$ pmol of choline per milligram of protein over $5 \mathrm{~min}$ for $\mathrm{CHT}$ and L531A-CHT, respectively. Data (percentage of control uptake in the absence of SIN-1) are expressed as mean \pm SEM of four or five independent experiments, each with triplicate measurements. Statistical analysis was performed on the data before it being normalized to vehicletreated control uptake for each group; asterisks denote statistically significant differences at $p \leq 0.05$.

activity of SY5Y-L531A-CHT. Consistent with our previous findings (Pinthong et al., 2008), choline uptake was $49 \pm 14 \%$ of control in SY5Y-CHT cells treated with $1 \mathrm{~mm}$ SIN-1, but L531A$\mathrm{CHT}$ was resistant to inhibition by $1 \mathrm{~mm}$ SIN-1, retaining $95 \pm$ $11 \%$ of control uptake activity. Figure 1 illustrates dose-response relationships for choline uptake in SIN-1-treated retinoic aciddifferentiated SY5Y-CHT and SY5Y-L531A-CHT cells. A statistically significant difference was seen between SY5Y-CHT and SY5Y-L531A-CHT dose-response curves at $1 \mathrm{~mm} \mathrm{SIN-1.} \mathrm{It} \mathrm{is}$ important to note that, as $1 \mathrm{~mm}$ SIN-1 did not alter activity of L531A-CHT, it is unlikely that inhibition of CHT is due to oxidative or nitrosative modification of CHT proteins.

At higher doses of SIN-1 (5 mM), inhibition of the two transporters did not differ significantly ( 49 and $33 \%$ of control uptake for L531A-CHT and CHT, respectively) (data not shown), but this is likely due to nonspecific effects of SIN-1 such as the collapse of ionic gradients required for active uptake of choline or compromised membrane integrity, rather than to a direct effect of SIN-1 on CHT. We showed previously that the decrease in CHT activity mediated by acute exposure of cells to $1 \mathrm{~mm}$ SIN-1 is not due to damage to cell integrity or toxicity monitored by LDH release and the MTT assay (Pinthong et al., 2008). Also, the SIN-1-mediated inhibition of choline uptake occurs rapidly; choline uptake activity assayed at 5 min of SIN-1 exposure reveals a significant decrease in CHT activity (data not shown).

\section{Acute SIN-1 treatment decreases cell surface levels of wild-type CHT, but not L531A-CHT}

Two approaches, equilibrium binding of the CHT antagonist $\left[{ }^{3} \mathrm{H}\right] \mathrm{HC}-3$ and plasma membrane protein biotinylation, were used to measure the SIN-1 effects on the amount of CHT protein at the cell surface. Plasma membrane levels of wild-type and L531A-CHT were assayed in SH-SY5Y cells after 15 min incubation with either vehicle or $1 \mathrm{~mm}$ SIN-1. Consistent with the data shown in Figure 1 on the effects of SIN-1 on choline uptake activity, CHT and L531A-CHT responded differentially to exposure to this $\mathrm{ONOO}^{-}$donor. In the first approach, specific binding of $\left[{ }^{3} \mathrm{H}\right] \mathrm{HC}-3$ was significantly decreased in SIN-1-treated SY5Y-CHT cells to $69.0 \pm 3.7 \%$ of vehicle-treated cells $(n=3$

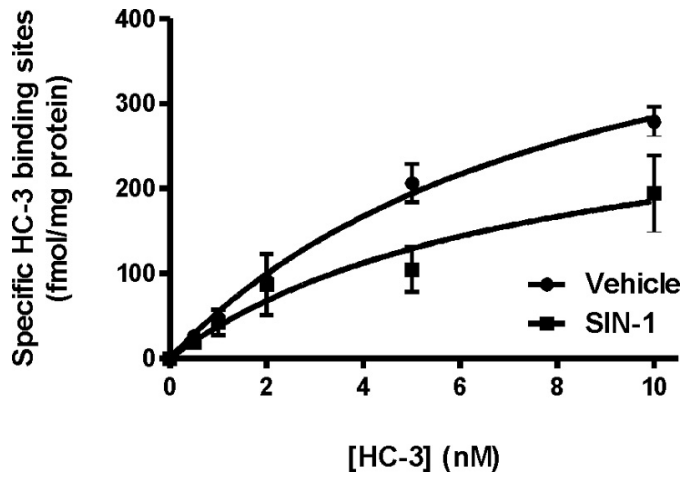

Figure 2. SIN-1 decreases CHT activity by changing the number of transporter proteins at the cell surface, but not altering binding of solute to transporters. Kinetic parameters for cell surface $\left[{ }^{3} \mathrm{H}\right] \mathrm{HC}-3$ binding in HEK-CHT cells were estimated using between 0.5 and $10 \mathrm{~nm} \mathrm{HC}-3$. Data were calculated as femtomoles of $\mathrm{HC}-3$ bound per milligram of protein, and expressed as mean \pm SEM $(n=4)$. Data were fit by Michaelis-Menten nonlinear regression analysis of individual experiments, and differences between vehicle and SIN-1 treatments were examined by comparison of the apparent binding affinity for ligand $\left(K_{\mathrm{D}}\right)$ and the number of $\mathrm{CHT}$ sites $\left(B_{\max }\right)$ values of the two curves. While the apparent $K_{\mathrm{D}}$ for $\mathrm{HC}-3$ binding to $\mathrm{CHT}$ did not differ between vehicle- and SIN-1-treated cells, the $B_{\max }$ for $\left[{ }^{3} \mathrm{H}\right] \mathrm{HC}-3$ binding decreased to $\sim 50 \%$ of the control value in cells treated with $1 \mathrm{~mm}$ SIN-1 ( $p<0.05$, Student's $t$ test).

independent experiments; $p=0.004)$. By comparison, there were no differences in specific binding of $\left[{ }^{3} \mathrm{H}\right] \mathrm{HC}-3$ between vehicleand SIN-1-treated SY5Y-L531A-CHT cells (111.4 $\pm 15.6 \%$ of vehicle-treated cells; $n=4$ independent experiments; $p=0.64$ ). With the second approach, immunoblots of biotinylated cell surface proteins were used to assess the plasma membrane levels of CHT in vehicle- and SIN-1-treated SY5Y-CHT and SY5YL531A-CHT cells. Cell surface levels of wild-type CHT are significantly reduced in SIN-1-treated SY5Y-CHT cells to $61.5 \pm$ $13.7 \%$ when compared with vehicle-treated cells ( $n=4$ independent experiments; $p=0.005$ ). By comparison, cell surface levels of mutant L531A-CHT do not differ between control and SIN-1 treatment groups in SY5Y-L531A-CHT cells (108.5 $\pm 14.9 \%$ of vehicle-treated cells; $n=4$ independent experiments; $p=0.42$ ). Statistical analysis was by paired Student's $t$ test. Thus, based on both $\left[{ }^{3} \mathrm{H}\right] \mathrm{HC}-3$ binding and protein biotinylation data, cell surface levels of CHT were significantly decreased by SIN-1. Neither method revealed a significant change in the plasma membrane levels of L531A-CHT protein in SIN-1-treated SH-SY5Y cells when compared with controls.

For kinetic analysis of the effects of SIN- 1 on $\left[{ }^{3} \mathrm{H}\right] \mathrm{HC}-3$ binding to wild-type $\mathrm{CHT}$ protein, HEK-CHT cells were used as they express higher levels of $\mathrm{CHT}$, thereby facilitating quantification of ligand binding. Analysis of $\left[{ }^{3} \mathrm{H}\right] \mathrm{HC}-3$ (0.5-10 nM) binding to CHT was performed following treatment with or without $1 \mathrm{~mm}$ SIN-1 (Fig. 2) to establish whether the observed decrease in cell surface binding of $\mathrm{HC}-3$ was due to a change in binding affinity $\left(K_{\mathrm{D}}\right)$ of HC-3 for its target on CHT or only to a change in the plasma membrane level of CHT $\left(B_{\max }\right)$. The apparent $K_{\mathrm{D}}$ for HC-3 binding to CHT did not differ between vehicle- and SIN1 -treated cells ( $4 \pm 0.9$ and $4 \pm 0.7 \mathrm{nM}$, respectively). However, SIN-1 did reduce the cell surface CHT levels with the $B_{\max }$ for $\left[{ }^{3} \mathrm{H}\right] \mathrm{HC}-3$ binding decreased by $\sim 50 \%$ from $473 \pm 82$ in control cells to $226 \pm 71 \mathrm{fmol}$ of $\left[{ }^{3} \mathrm{H}\right] \mathrm{HC}-3$ bound/mg protein by SIN-1 $(p<0.05$; Student's $t$ test $)$.

\section{Blockade of clathrin-mediated endocytosis attenuates inhibition of CHT by SIN-1}

Major endocytic pathways for cell surface proteins can be selectively downregulated by expression in the cells of DN proteins 
A

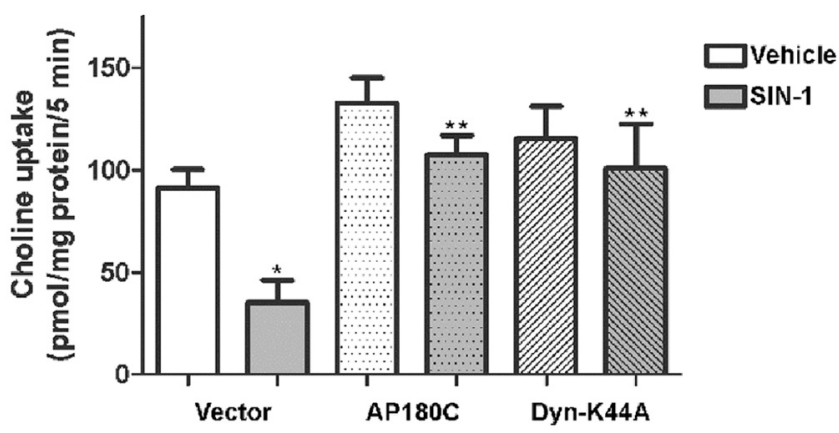

B

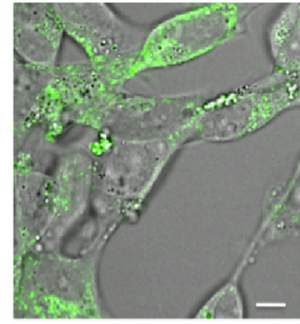

Vector

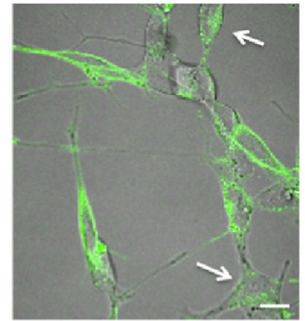

AP180C

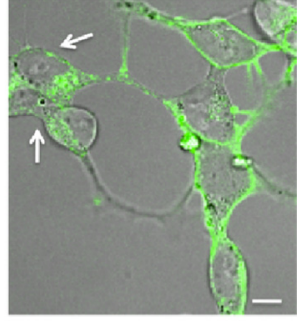

Dyn-K44A
Figure 3. Inhibition of CHT activity by SIN-1 is attenuated by AP180C and Dyn-K44A. Selected endocytic pathways were inhibited in SY5Y-CHT cells using DN proteins. A, SY5Y-CHT cells were transiently transfected to express either empty vector pCDNA3.1 as a control, AP180C to block the clathrin-dependent pathway, or Dyn-K44A to block dynamin-dependent pathways. HC-3-sensitive choline uptake was assayed in transfected cells after 20 min of either vehicle or $1 \mathrm{~mm} \mathrm{SIN-1} \mathrm{treatment;} \mathrm{HC-3-}$ sensitive choline uptake was determined as the difference between uptake in the absence and presence of $1 \mu \mathrm{m} \mathrm{HC}-3$, and expressed as picomoles/milligrams of protein per $5 \mathrm{~min}$. Data were analyzed using a repeated-measures one-way ANOVA with Tukey's post hoc multiple-comparisons test. Data are expressed as the mean \pm SEM of five independent experiments. A single asterisk $\left(^{*}\right)$ denotes when SIN-1 treatment is significantly different from vehicle treatment ( $\left.p \leq 0.05\right)$, and a double asterisk $\left(^{* *}\right)$ indicates when SIN-1-treated groups are significantly different from each other $(p \leq 0.05)$. $\boldsymbol{B}$, Live cells transfected with plasmids encoding either AP180C or Dyn-K44A had visible accumulation of Zenon 488-labeled CHT at the cell surface, whereas cells that were either transfected with the empty vector pcDNA3.1 as the control or that did not become transfected in the DN-transfected plates had substantial internalization of fluorescently labeled CHT into subcellular compartments (these latter cells are identified by white arrows in the AP180C and Dyn-K44A samples). Scale bars: Vector and Dyn-K44A, $5 \mu \mathrm{m} ; \mathrm{AP180C}, 10 \mu \mathrm{m}$.
CHT internalizes into Rab5a-positive organelles in control and SIN-1-treated cells We found previously that acute exposure of cells to the $\mathrm{ONOO}^{-}$donor SIN-1 alters choline uptake activity by increasing the rate at which CHT proteins undergo endocytosis, potentially accounting for the reduction of $\mathrm{CHT}$ at the plasma membrane (Pinthong et al., 2008). The mechanism by which this occurs is not known, but it could be due to modified interaction of CHT with other proteins and/or internalization machinery such as endocytic and trafficking adaptor or Rab proteins. To address this, we assessed the distribution of CHT internalized from the cell surface to subcellular organelles in live vehicle- and SIN-1-treated SY5Y-CHT and SY5Y-L531A-CHT cells that coexpress GFP-tagged Rab5a as a marker of early endosomes. As shown in Figure $4 A--C$, wild-type CHT entered vehicletreated cells in Rab5a-positive vesicles, showing a high level of colocalization with this marker in punctate structures. Acute exposure of SY5Y-CHT cells to SIN-1 did not appear to substantially change the level of internalized CHT colocalizing with Rab5a (Fig. $4 D--F$ ). It is interesting to note that the Rab5a-positive vesicles appeared to be larger in SIN-1-treated cells. By comparison, there was negligible internalization of mutant CHT to Rab5apositive endosomes in either vehicle- or SIN-1-treated SY5Y-L531A-CHT cells during the experimental observation pe$\operatorname{riod}$ (Fig. $4 G-L$ ).

\section{CHT is present in the late endosome/}

that block the function of critical proteins. In these experiments, we inhibited clathrin-mediated endocytosis with AP180C (Ford et al., 2001) and used Dyn-K44A as a blocker of both dynamin- and clathrin-dependent endocytosis (Damke et al., 2001) to examine the routes by which CHT internalizes from the plasma membrane during acute SIN-1 exposure. SY5Y-CHT cells were transiently transfected with empty vector pcDNA3.1 (control) or a plasmid encoding one of the DN proteins, and then choline uptake activity was assayed in the absence and presence of SIN-1.

Figure $3 A$ reveals that the expression of AP180C blocked the SIN-1 effect, indicating that clathrin-mediated endocytosis is involved in the response of CHT to SIN-1 in these cells. Dyn-K44A also attenuated SIN-1-mediated inhibition of CHT. To verify that these DN proteins functioned to block CHT internalization, we imaged cells coexpressing CHT and either AP180C or Dyn-K44A; control cells were transfected with empty vector pcDNA3.1. Figure $3 B$ illustrates that cells that were transfected to express either of these DN proteins displayed increased CHT localization at the plasma membrane and had substantially reduced subcellular levels of the transporter protein when compared with cells not expressing either of the DN proteins (denoted by arrows) or that were transfected with empty vector (control).

\section{lysosome system under both vehicle and SIN-1 treatment}

Confocal imaging where CHT trafficking was labeled in live cells was used to further address the movement of CHT into late endosomes and lysosomes, and to assess whether this was altered by SIN-1 treatment. Extensive colocalization was observed between CHT and Rab7-GFP (Fig. 5), Rab9-YFP (Fig. 6), and endogenous Lamp-1 (Fig. 7) in both vehicle-treated control cells and cells that were acutely exposed to $1 \mathrm{~mm}$ SIN-1; Rab7 localizes to both early and late endosomes and is a cargo-sorting protein required for ham and Ceresa, 2009), whereas Rab9 is associated with late endosomes and Lamp-1 with lysosomes. Colocalized proteins appear yellow in the overlay images in these figures.

As illustrated in Figure 5, CHT colocalizes with the late endosomal marker Rab7-GFP, and the amount of this colocalization was not substantially altered by SIN-1 treatment. To further assess the amount of $\mathrm{CHT}$ in late endosomes and lysosomes under SIN-1 and vehicle treatments, we used a quantitative approach to determine the relative amount of CHT colocalization with Rab9YFP or endogenous Lamp- 1 by a method described by Lorenzen et al. (2010). An example of this analysis is shown in Figure 6 for CHT and Rab9-YFP. A threshold intensity was set that filters for the brightest $2 \%$ of pixels of CHT (red channel), indicated to the protein transfer from late endosomes to lysosomes (Vanlanding- 
right of the vertical yellow line on the histogram, that also fall within the brightest $2 \%$ of pixels of Rab9-YFP (green channel), indicated above the horizontal line on the histogram. The percentage of these pixels that are both red and green were then determined as the percentage of the two proteins within this population that are colocalized; these Colocalized Pixels are identified in a separate colocalization channel (white) shown in the rightmost column. Similar analysis for colocalization of CHT (green channel) and Lamp-1 (red channel) is given in Figure 7. In these experiments, we found that CHT colocalizes with both the late endosomal marker Rab9-YFP and the lysosomal marker Lamp-1 under both vehicle and SIN-1 treatments. Quantification of the pixels within the colocalization channel for each image revealed that, in vehicle-treated cells, $51 \pm 2.3,59 \pm 1.5$, and $57 \pm 2.1 \%$ of CHT colocalizes with Rab9-YFP at 0,30 , and $60 \mathrm{~min}$, respectively, and in SIN-1treated cells these values were $52 \pm 1.8$, $52 \pm 1.5$, and $55 \pm 1.7 \%$ at 0,30 , and 60 min, respectively. The percentage for $\mathrm{Co}-$ localization of CHT with Rab9-YFP in vehicle-treated cells at $30 \mathrm{~min}$ was significantly greater than at $0 \mathrm{~min}$ (Fig. 6G), but no other statistically significant differences were found between these groups. For CHT and Lamp-1, analysis of the colocalization channels for images of vehicle-treated cells revealed that, at 0,30 , and $60 \mathrm{~min}$, there were $40 \pm 2.3,31 \pm 1.6$, and $38 \pm 1.3 \%$ colocalization, respectively, compared with SIN-1-treated cells at 0, 30, and $60 \mathrm{~min}$, in which there were $36 \pm 1.9$, $31 \pm 1.7$, and $36 \pm 1.6 \%$ colocalization, respectively; there were no statistically significant differences between these groups (Fig. $7 G$ ). The high level of colocalization of CHT with both Rab9-YFP and Lamp-1 suggests that CHT transits through the late endosomal/lysosomal pathway. Moreover, these data also suggest that SIN-1 does not alter CHT trafficking in this protein-degradative pathway.

\section{Inhibition of proteasomes, but not} lysosomes, blocks the SIN-1 effect on choline uptake

To further determine whether SIN-1 alters CHT trafficking through the late endosome/lysosome pathway and to investigate whether SIN-1 targets CHT to an alternate route for degradation by the proteasome, proteolytic activity of lysosomes and proteasomes were blocked using a pharmacological approach. In this experiment, separate sets of cells were treated with either the lysosome inhibitors chloroquine or bafilomycin A1 or with the proteasome inhibitors lactacystin or MG-132, and then choline uptake activity was assayed in the absence and presence of $1 \mathrm{~mm}$ SIN-1. Figure $8, A$ and $B$, shows that neither chloroquine nor surface. Scale bars, $5 \mu \mathrm{m}$.
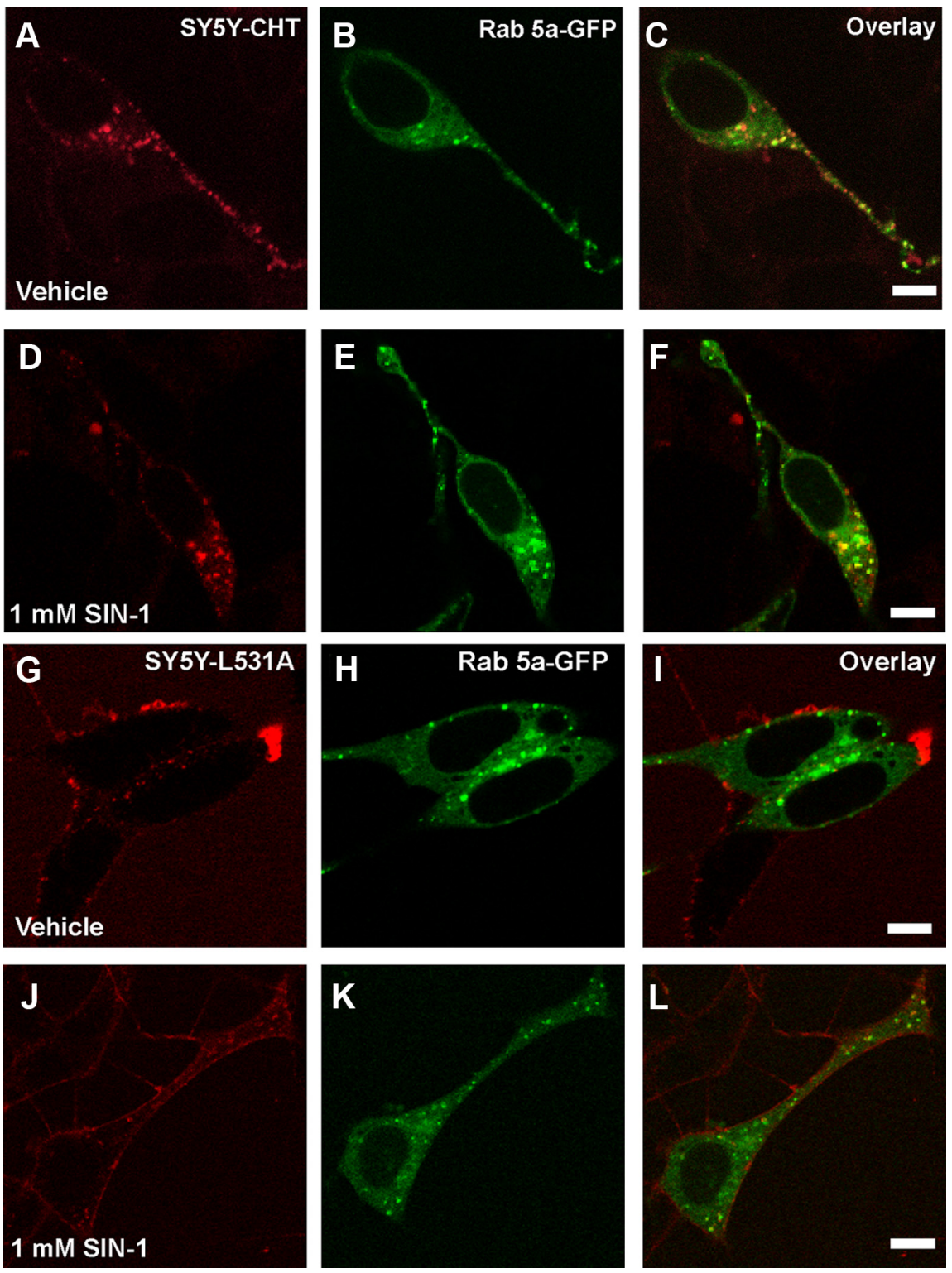

Figure 4. Wild-type CHT but not L531A-CHT traffics to Rab5a-positive subcellular compartments in live cells. Confocal images showing Zenon 555-labeled CHT (red) and GFP-tagged Rab5a (green) distribution in vehicle-treated cells and cells treated with 1 mM SIN-1 for 15 min. Colocalized CHT and Rab5a appear as yellow. Zenon 555 dye conjugated with rabbit anti-FLAG antibody was added to the medium bathing the cells for $10 \mathrm{~min}$ at $37^{\circ} \mathrm{C}$ where it could bind to the extracellular FLAG epitope on CHT, and then the movement of fluorescently labeled proteins into cells was tracked at $10 \mathrm{~min}$ after the addition of treatment. Similar levels of colocalization of CHT with Rab5a-GFP were observed in both vehicle $(\boldsymbol{A}-\boldsymbol{C})$ - and SIN-1 (D-F)-treated cells expressing wild-type CHT. Interestingly, the subcellular organelles containing CHT-Rab5a in SIN-1-treated cells were larger than those observed in the vehicle-treated cells. In support of our hypothesis, L531A-CHT does not appear to internalize in either vehicle $(\mathbf{G}-\boldsymbol{I})$ - or SIN-1 $(\boldsymbol{J}-\boldsymbol{L})$-treated cells, and the accumulation of Zenon-labeled L531A-CHT can be observed at the cell

bafilomycin A1 modified the level of inhibition of CHT activity by SIN-1. This is a further indication that movement of CHT to the lysosome for degradation is not altered by SIN-1 treatment. An interesting observation is that that chloroquine treatment caused a statistically significant increase in choline uptake activity when compared with vehicle-treated cells (i.e., no chloroquine) (Fig. $8 \mathrm{~A}$ ). This is consistent with the concept that CHT is normally trafficked to and degraded by the lysosome, and suggests that inhibition of this degradative process allows more CHT to be available for recycling back to the cell surface. Importantly, both of the proteasome inhibitors lacta- 

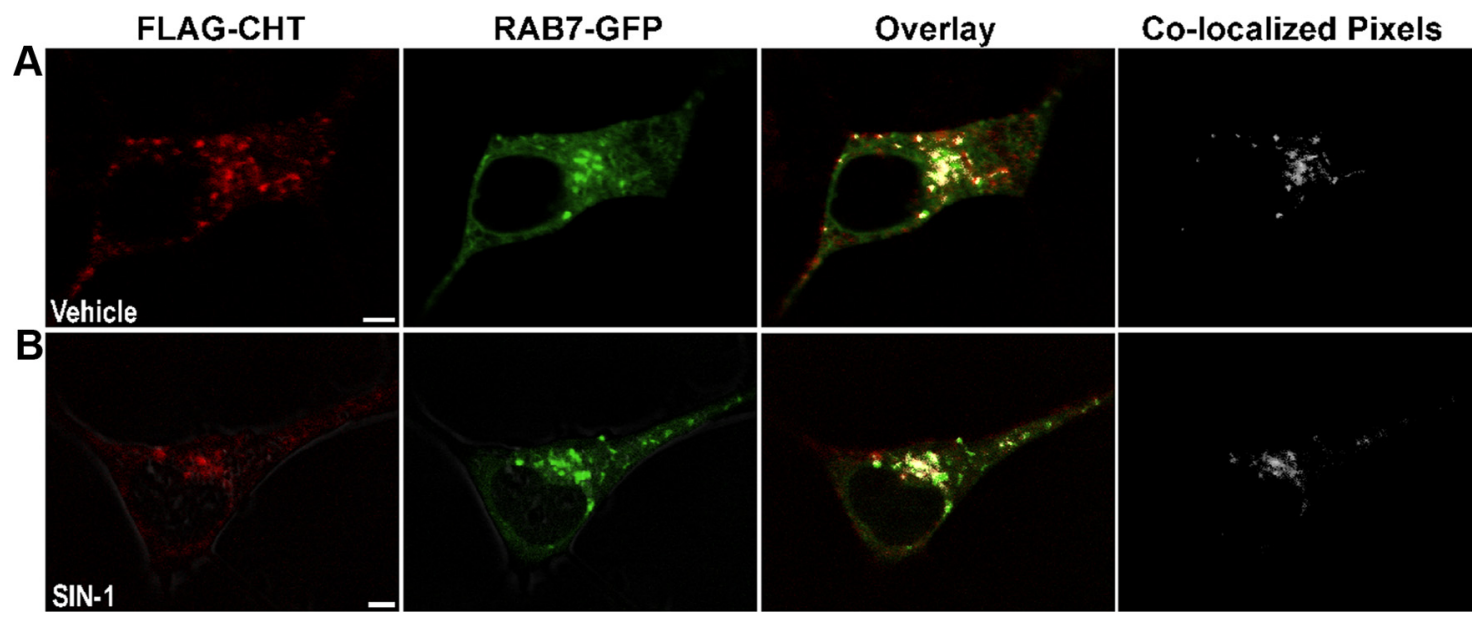

Figure 5. CHT colocalization with Rab7-GFP is seen in vehicle-treated ( $\boldsymbol{A}$ ) and SIN-1-treated ( $\boldsymbol{B}$ ) SY5Y-CHT cells. Confocal images show Zenon 555-labeled CHT (red) and GFP-tagged Rab7 (green) distribution in vehicle-and $1 \mathrm{~mm}$ SIN-1-treated SY5Y-CHT cells. Colocalized CHT and Rab7 appear as yellow. Zenon 555 dye conjugated to rabbit anti-FLAG antibody was added to the medium bathing the cells for $10 \mathrm{~min}$ at $37^{\circ} \mathrm{C}$ where it could bind to the FLAG epitope on the $\mathrm{N}$ terminus of $\mathrm{CHT}$ located at the cell surface. This facilitated tracking of the internalization and distribution of $\mathrm{CHT}$ proteins in cells after 15 min of either vehicle or SIN-1 treatment. Scale bar, $3 \mu \mathrm{m}$.

cystin and MG-132 attenuated the SIN-1-mediated inhibition of CHT (Fig. 8C,D), indicating that the proteasome may play a role in the inhibition of choline uptake activity observed in SIN-1-treated cells.

\section{Ubiquitination of CHT is enhanced in SIN-1-treated cells}

Finally, we investigated whether CHT is ubiquitinated and whether this is modified by acute SIN-1 treatment of SH-SY5YCHT cells. Ubiquitination is a reversible posttranslational modification of cellular proteins that can alter their subcellular trafficking or may target them to either lysosomes or proteasomes for degradation. In these experiments, we used either $\mathrm{SH}$ SY5Y cells stably expressing the empty vector pcDNA3.1 and not CHT to serve as a negative control or SY5Y-CHT stably expressing FLAG-tagged CHT protein. Cells were treated with vehicle or $1 \mathrm{~mm}$ SIN-1 for $20 \mathrm{~min}$, and FLAG-CHT was recovered from lysates using anti-FLAG affinity resin. Figure 9 (bottom two panels) shows a representative immunoblot that was probed for ubiquitin using anti-ubiquitin antibody, stripped, and reprobed for FLAG-CHT using anti-CHT antibody. The anti-ubiquitin immunoblot reveals faint protein bands positive for ubiquitin in both the vehicle- and SIN-1-treated cells. The most robust ubiquitin-positive band appears in the SIN-1-treated cells at an apparent molecular mass of $\sim 80 \mathrm{kDa}$; a corresponding band is evident in the anti-CHT blot (denoted by the arrows). No ubiquitinated or CHT-positive bands were detected in negative control "vector" cells. Despite CHT having a molecular weight of $\sim 62 \mathrm{kDa}$, this protein generally appears on SDS-PAGE as a diffuse band with an apparent molecular mass of $\sim 50 \mathrm{kDa}$. Based on a shift in the mass of FLAG-CHT of $\sim 30 \mathrm{kDa}$, this suggests that SIN-1 treatment may lead to the addition of approximately four ubiquitin molecules to $\mathrm{CHT}$, indicating that this could be due to multiple mono-ubiquitin or di-ubiquitin molecules or a short polyubiquitin chain.

\section{Discussion}

The mechanisms by which SIN-1 could alter CHT activity include structural modification of the protein by nitration of tyrosine residues or $S$-nitrosylation or oxidation of cysteine residues, changes in cell surface levels of CHT proteins due to altered subcellular trafficking or localization or degradation, dissipation of transmembrane electrochemical gradients, or loss of cell viability. We made novel findings in the present study that support our prediction that CHT inhibition by SIN-1 is mediated by changes to protein trafficking events, since the activity of a CHT mutant that does not undergo clathrin-mediated endocytosis is not affected by SIN-1. We also found that with SIN-1 treatment CHT internalizes from the cell surface by a clathrin- and dynamin-mediated process, since dominant-negative proteins that block either clathrin or dynamin function attenuate SIN-1mediated inhibition of CHT. Moreover, we show for the first time that CHT proteins move through the endosomal-lysosomal pathway colocalizing with compartment markers, but that SIN-1 does not alter this trafficking. Our studies reveal that CHT normally undergoes lysosomal degradation, since lysosome inhibitors enhance choline uptake activity likely by increasing CHT availability for recycling to the cell surface. Importantly, however, proteasome, but not lysosome, inhibitors attenuate SIN-1mediated inhibition of choline uptake, indicating that proteasomal degradation has a role in CHT protein disposition in cells exposed to SIN-1. Finally, we demonstrate for the first time that CHT protein undergoes ubiquitination, and this is enhanced by SIN-1 treatment.

We made the critical observation that mutant L531A-CHT is resistant to the SIN-1-mediated inhibition that is seen with wildtype CHT. Thus, inactivation of CHT function by SIN-1 is not likely due to oxidative or nitrosative modification of essential amino acids, thereby highlighting the importance of changes in intracellular trafficking of CHT proteins in its response to SIN-1. These findings for CHT inhibition differ from mechanisms by which hDAT activity is decreased in $\mathrm{ONOO}^{-}$-treated cells or hSERT is inhibited in cells exposed to NO and related compounds, including peroxynitrite. With hDAT, inhibition by $\mathrm{ONOO}^{-}$is caused by modification of a cysteine residue that is critical for transporter function (Park et al., 2002). It is interesting, however, that $\mathrm{ONOO}^{-}$does not block hDAT directly, as it was shown that inhibition is caused by a highly reactive dopamine-quinone moiety formed by reaction of $\mathrm{ONOO}^{-}$with intracellular dopamine (Whitehead et al., 2001). Similarly, hSERT inhibition may involve $S$-nitrosylation of cysteine residues since inhibition was attenuated by addition of L-cysteine to 


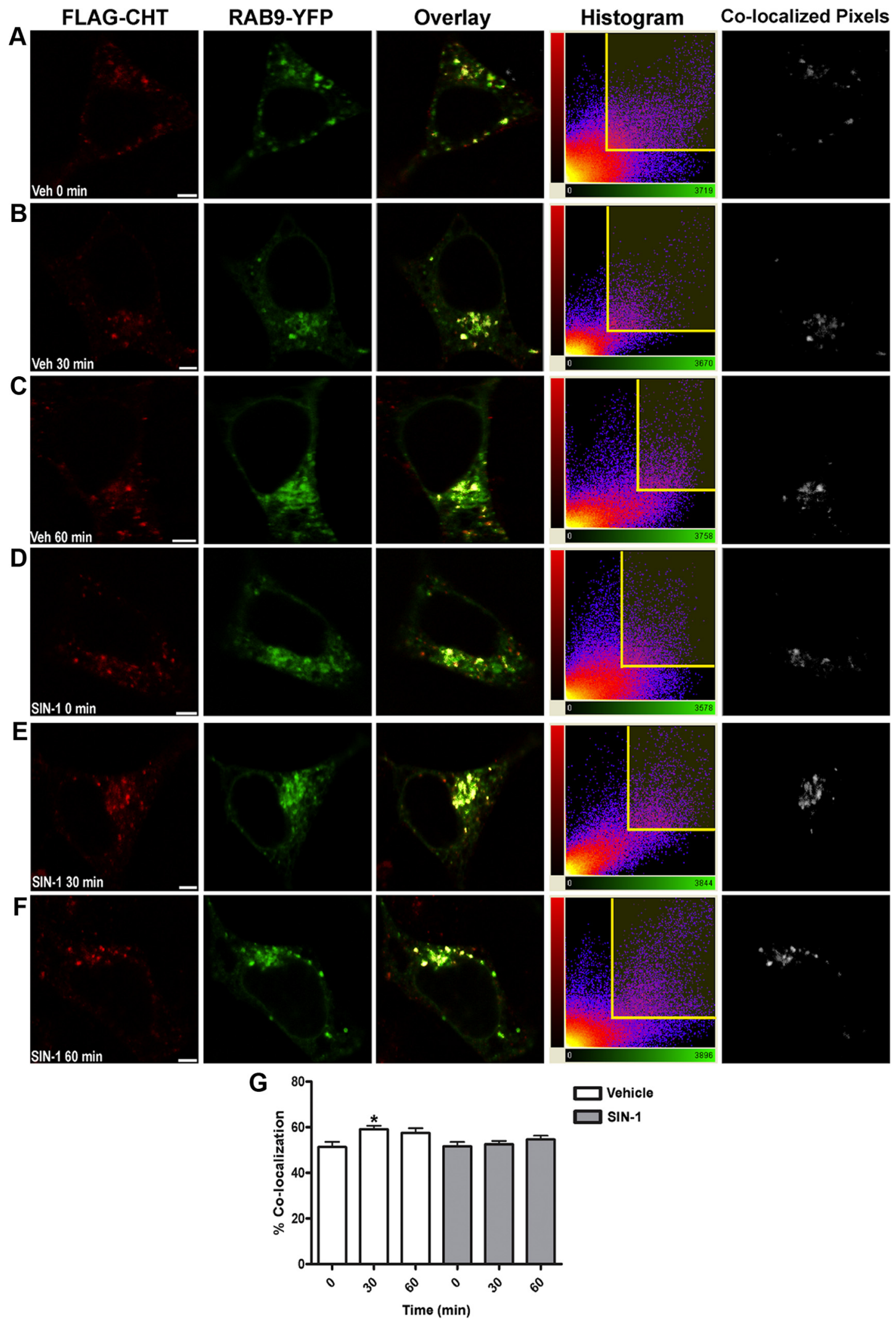

Figure 6. CHT colocalization with Rab9-YFP in SY5Y-CHT cells is not changed by SIN-1 treatment. Confocal images show Zenon 555-labeled CHT (red) and YFP-tagged Rab9 (green) distribution in vehicle-and $1 \mathrm{~mm}$ SIN-1-treated SY5Y-CHT cells. Zenon 555 dye conjugated to rabbit anti-FLAG antibody was added to the medium bathing the cells for 15 min where it could bind to the FLAG epitope of the extracellular N terminus of $\mathrm{CHT}$ proteins that were located at the cell surface. This facilitated tracking of the internalization and distribution of CHT proteins in cells at 0,30 , and 60 min under either vehicle $(\boldsymbol{A}-\mathbf{C})$ or SIN-1 (D-F) treatment. Colocalized CHT and Rab9-YFP appear as yellow in the Overlay images, and the histograms resulting from analysis of these images are shown (G). CHT and Rab9-YFP pixels that were determined to be colocalized in the colocalization channel are shown as white in the Colocalized Pixels images. To quantify colocalization, the brightest 2\% of the red pixels (to the right of the vertical yellow line on the histograms) and green pixels (above the horizontal yellow line on the histograms) were selected. Imaris software was used to quantify the colocalization of CHT with Rab9-YFP. Data were analyzed by one-way ANOVA followed by Tukey's posttest and are expressed as mean \pm SEM for a minimum of 40 cells per treatment group from four independent experiments (a single asterisk denotes $p \leq 0.01$ ). Scale bar, $3 \mu \mathrm{m}$. 


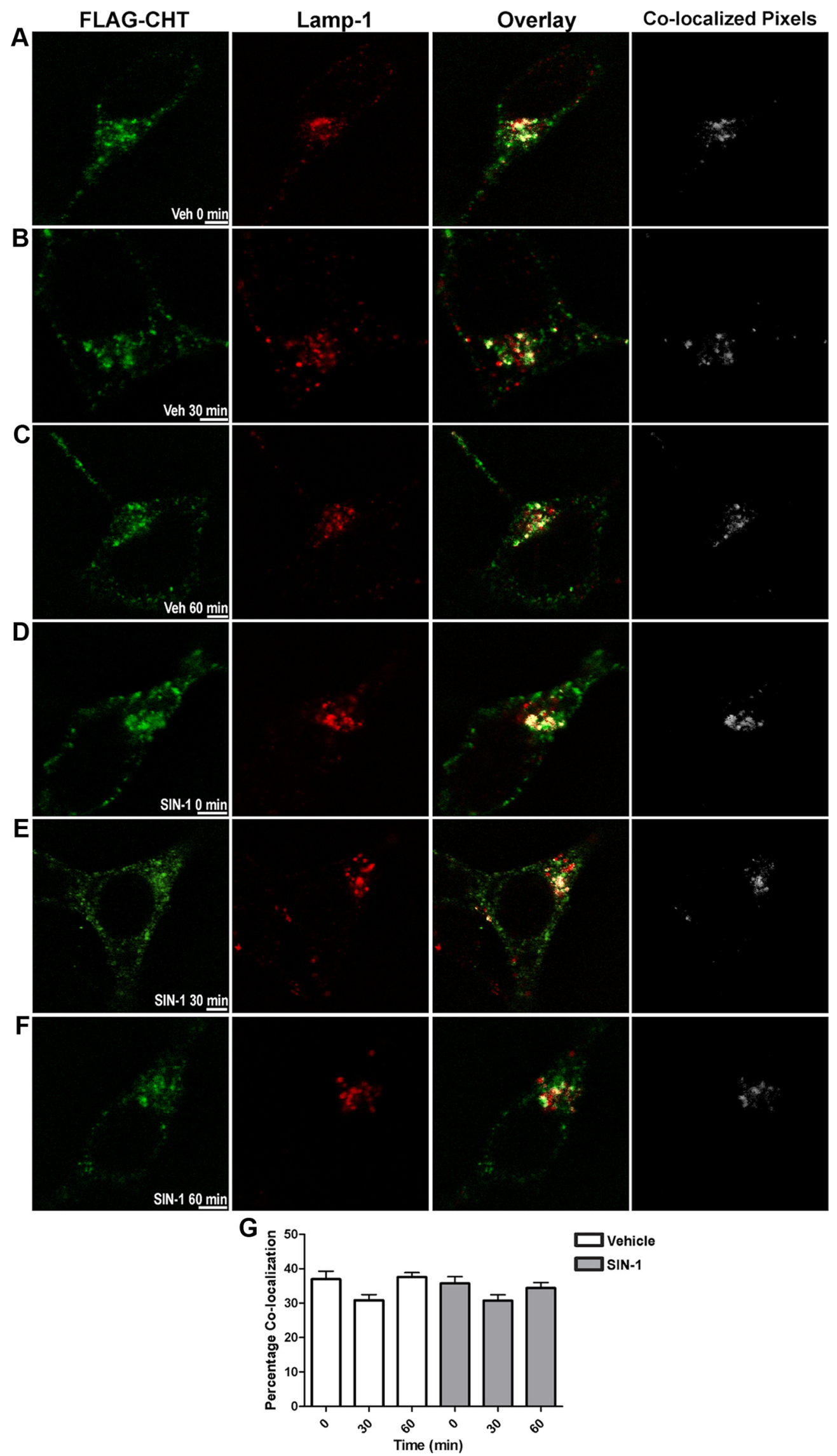

Figure 7. CHT colocalization with Lamp-1 is seen in vehicle- and SIN-1-treated SY5Y-CHT cells. Confocal images show Zenon 488-labeled CHT (green) and Alexa Fluor 555-labeled Lamp-1 (red) distribution in vehicle-treated and $1 \mathrm{~mm}$ SIN-1-treated SY5Y-CHT cells. Zenon 488 dye conjugated to rabbit anti-FLAG antibody was added to the medium bathing the cells (Figure legend continues.) 
A
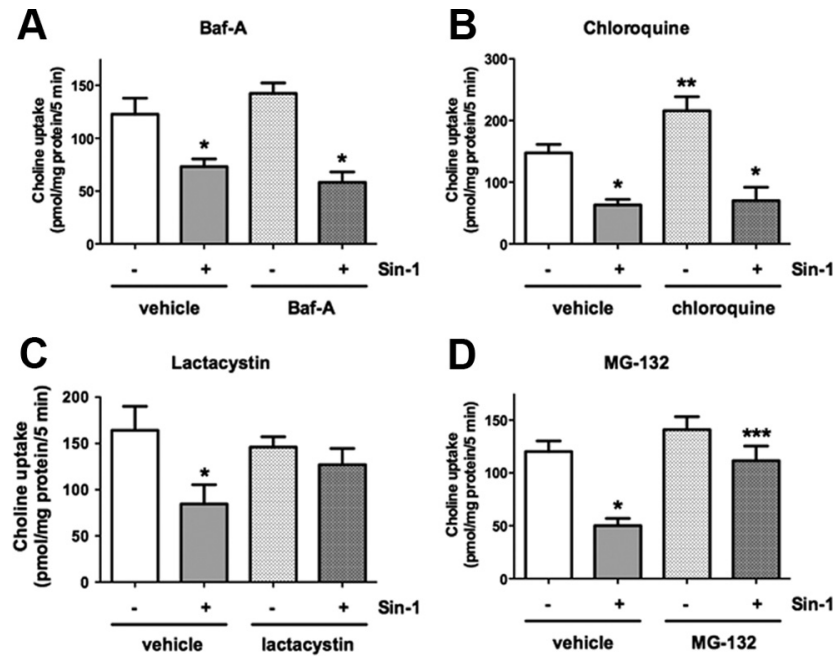

Figure 8. Inhibition of $\mathrm{CHT}$ activity by SIN-1 is attenuated by proteasome inhibitors lactacystin and MG-132, but not by lysosome inhibitors chloroquine and Baf-A. Proteolytic activity of the lysosome and proteasome were blocked using a pharmacological approach. $A$, Cells were treated with either DMSO or $20 \mathrm{~nm}$ Baf-A dissolved in complete medium for $24 \mathrm{~h}$ at $37^{\circ} \mathrm{C}$. HC-3-sensitive choline uptake was assayed in cells after 20 min of either vehicle or $1 \mathrm{~mm} \mathrm{SIN-1}$ treatment. HC-3-sensitive choline uptake was determined as the difference between uptake in the absence and presence of $1 \mu \mathrm{m} \mathrm{HC}-3$, and expressed as picomoles/milligram of protein per 5 min. Data are expressed as mean \pm SEM of five independent experiments. $\boldsymbol{B}$, Cells were treated with either double-distilled $\mathrm{H}_{2} \mathrm{O}$ or $50 \mu \mathrm{m}$ chloroquine dissolved in complete medium for $2 \mathrm{~h}$ at $37^{\circ} \mathrm{C}$. HC-3-sensitive choline uptake was assayed in cells after $20 \mathrm{~min}$ of either vehicle or $1 \mathrm{~mm}$ SIN-1 treatment. Data are expressed as mean \pm SEM of five independent experiments. C, Cells were treated with either double-distilled $\mathrm{H}_{2} \mathrm{O}$ or $0.5 \mu \mathrm{m}$ lactacystin dissolved in complete medium for $1 \mathrm{~h}$ at $37^{\circ} \mathrm{C}$. HC-3-sensitive choline uptake was assayed in cells after $20 \mathrm{~min}$ of either vehicle or $1 \mathrm{~mm}$ SIN-1 treatment. Data are expressed as mean \pm SEM of five independent experiments. $\boldsymbol{D}$. Cells were treated with either DMSO or $5 \mu \mathrm{M}$ MG-132 in complete medium for $30 \mathrm{~min}$ at $37^{\circ} \mathrm{C}$. Data were analyzed using a repeated-measures one-way ANOVA with Tukey's post hoc multiple-comparisons test. Data are expressed as mean \pm SEM of four independent experiments. ${ }^{*}$ SIN- 1 treatment is significantly different from vehicle treatment $(p<0.05)$. ${ }^{* *}$ Drug treatment is significantly different from vehicle treatment $(p<0.05)$. ${ }^{* *}$ SIN-1treated groups are significantly different from each other $(p<0.05)$.

the incubation buffer (Bryan-Lluka et al., 2004); L-cysteine acts as a "sink" by providing excess thiol groups to interact with reactive compounds (Kaye et al., 1997). CHT is relatively cysteine poor, having only five cysteine residues in human CHT (Apparsundaram et al., 2000) compared with 13 in hDAT (Giros et al., 1991) and 18 in hSERT (Ramamoorthy et al., 1993), but it is not known whether any of these cysteines are critical for $\mathrm{CHT}$ function. With regard to nitration of tyrosine residues in $\mathrm{CHT}$, we did not detect this in SIN-1-treated cells by immunoblot using nitrotyrosine antibodies (Pinthong et al., 2008).

We reported that SIN-1 enhances CHT endocytosis from plasma membrane, thereby decreasing its cell surface levels and reducing choline uptake capacity (Pinthong et al., 2008). Now,

$\leftarrow$

(Figure legend continued.) for 15 min where it could bind to the FLAG epitope of the N terminus of $\mathrm{CHT}$ located at the cell surface. This facilitated tracking of the internalization and distribution of CHT proteins in cells at 0,30 , and 60 min of either vehicle $(\boldsymbol{A}-\boldsymbol{C})$ or SIN-1 (D-F) treatment. The colocalization of $\mathrm{CHT}$ and LAMP-1 can be seen as yellow in the 0verlay panels. Images were analyzed as described in Figure 6 and in Materials and Methods. CHT and Lamp-1 that were determined to be colocalized in the colocalization channel are shown as white in the Colocalized Pixels images. Quantification of colocalized CHT and LAMP-1 is shown (G). Data were analyzed with a one-way ANOVA followed by Tukey's posttest and are expressed as the mean \pm SEM for a minimum of 40 cells per treatment from four independent experiments. Scale bar, $3 \mu \mathrm{m}$.

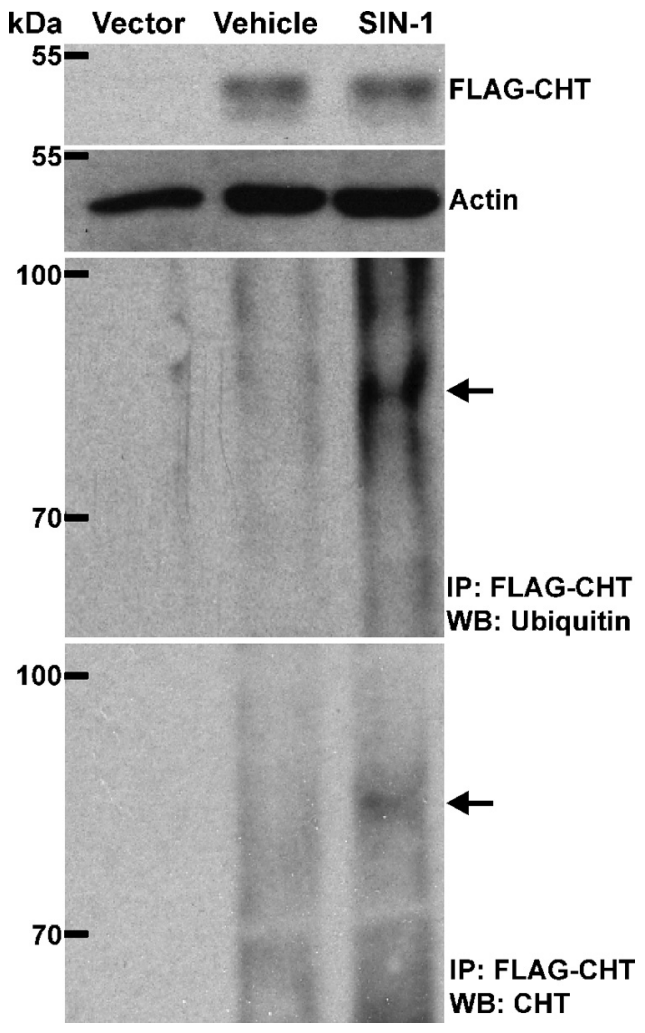

Figure 9. SIN-1 treatment causes CHT ubiquitination in SY5Y-CHT cells. FLAG-CHT was recovered from lysates prepared from SY5Y-CHT cells that were treated with either vehicle or $1 \mathrm{mM}$ SIN-1 for 20 min using anti-FLAG M2 affinity resin. Proteins were resolved by SDS-PAGE, transferred to PVDF membranes, and probed with either anti-ubiquitin or anti-CHT antibodies. Lysates prepared from SH-SY5Y cells that stably express the empty vector pCDNA3.1, and not CHT protein, were used as a negative control ("Vector" lane). Representative immunoblots show total FLAG-CHT and actin proteins in total cell lysates (top two panels). The bottom two panels illustrate FLAG-CHT proteins recovered on anti-FLAG affinity resin probed first with antiubiquitin antibody (1:5000), and then with anti-CHT antibody $(1: 10,000)$ following stripping. The arrows show ubiquitin and CHT-positive bands that appear at $\sim 80 \mathrm{kDa}$. The immunoblots shown are representative of data obtained in three independent experiments.

we show that CHT proteins internalize by clathrin- and dynamin-dependent mechanisms to Rab5a-positive early endosomes in both control and SIN-1-treated cells. Moreover, CHT levels in this compartment are not altered by SIN-1, suggesting that transporters are not retained there and move to other endosomal compartments. In relation to the mechanism underlying changes in CHT endocytosis, dynamin, which carries out endocytic budding of vesicles and membrane scission (Dessy et al., 2000; Conner and Schmid, 2003), undergoes S-nitrosylation at a critical cysteine residue in NO-treated cells. Importantly, this modification of dynamin causes accelerated endocytosis of plasma membrane proteins (Dessy et al., 2000; Wang et al., 2006). There are no data on the effects of $\mathrm{ONOO}^{-}$on dynamin function, but since $\mathrm{NO}$ can be rapidly converted to $\mathrm{ONOO}^{-}$and both of these highly reactive molecules can $S$-nitrosylate reactive cysteines, enhanced endocytosis associated with dynamin modification might also be mediated by $\mathrm{ONOO}^{-}$.

In addition to $\mathrm{CHT}$ proteins recycling back to the cell surface following endocytosis (Ferguson and Blakely, 2004; Ribeiro et al., 2006), other potential destinations for CHT in the neuron include being directed into the late endosomal pathway and/or lysosomes for degradation. This would effectively remove CHT proteins from the recycling pool that is important for supplying $\mathrm{CHT}$ to the cell surface and regulating choline uptake activity. We 
now show that some CHT proteins in both vehicle- and SIN-1treated cells move to colocalize with late endosome pathway small GTPases Rab7 and Rab9 and LAMP-1-positive lysosomes. The amount of CHT colocalized with these markers did not differ between vehicle- and SIN-1-treated cells; thus, SIN-1 does not promote $\mathrm{CHT}$ accumulation in these compartments. We also show for the first time that the normal site for CHT degradation is the lysosome, since the lysosome inhibitor chloroquine enhances choline uptake activity.

An unexpected finding is that the decreased CHT activity observed in SIN-1-treated cells was attenuated by proteasome blockers, suggesting that proteasomal protein degradation is involved in SIN-1-mediated loss of CHT function. Trafficking patterns for plasma membrane proteins to lysosomes or proteasomes may be altered under diverse conditions, including oxidative stress [glucose transporter GLUT1 (Fernandes et al., 2011)], single point mutations [low-density lipoprotein receptor (Martin de Llano et al., 2006)], and loss of intramolecular disulfide bonding [ATP-binding cassette transporter ABCG2 (Wakabayashi et al., 2007)]. While the mechanisms mediating these changes likely differ, there are similarities between our observations with CHT and effects of oxidative stress on GLUT1. Cell surface GLUT1 levels decrease during oxidative stress due to enhanced internalization and altered subcellular trafficking, with this linked to ubiquitination of GLUT1 and proteasome-dependent changes in protein kinase B (Akt) activation. Under these conditions, GLUT1 also undergoes monoubiquitination or di-ubiquitination (Fernandes et al., 2011).

Trafficking of solute transporters is also regulated by phosphorylation, and this is modulated by oxidative stress. Like CHT, GLUT4 glucose transporters are located mostly in intracellular vesicles under basal conditions and its plasma membrane levels are increased when solute is needed by the cell; insulin, ischemia, and hypoxia increase GLUT4 translocation (Fischer et al., 1997). Acute exposure of cardiomyocytes to $\mathrm{H}_{2} \mathrm{O}_{2}$ enhances plasma membrane GLUT4 levels by a mechanism involving activation of AMP-activated protein kinase and PI3-kinase/Akt (Horie et al., 2008). However, GLUT4 is not the substrate for these kinases, with regulatory proteins including Rab GAP AS160 being phosphorylated and then modulating GLUT4 disposition (Chavez et al., 2008). CHT in neurons is phosphorylated, and PKC regulates its activity and cell surface levels (Gates et al., 2004; Black et al., 2010), although the underlying mechanisms are unknown. Multiple kinases are altered by $\mathrm{ONOO}^{-}$, including activation of p38 kinase and Src kinase (Li et al., 1998; Di Stasi et al., 1999; OhHashi et al., 2001), but there are no data on the effects of kinases that are modulated by $\mathrm{ONOO}^{-}$on $\mathrm{CHT}$ disposition.

CHT interacts with amyloid precursor protein (APP) through its C-terminal tail, and APP has a role in regulating CHT subcellular trafficking in cholinergic neurons (Wang et al., 2007); APP serves as substrate for generation of $\beta$-amyloid, a critical feature in Alzheimer's disease pathogenesis, which is involved in production of oxidative stress in brain. APP is internalized from plasma membrane by endocytosis and moves through the endosomal pathway to lysosomes where it is cleaved by secretases. However, APP can also enter a novel, rapid transport pathway to move directly from the cell surface to lysosomes (Lorenzen et al., 2010). It is not known whether this trafficking is altered by oxidativenitrosative stress or what effect this could have on the function of its binding partner $\mathrm{CHT}$, but this raises important questions about the regulation of cholinergic presynaptic function by APP disposition and trafficking in neuropathology.

In summary, plasma membrane CHT levels are determined by the balance between cell surface recruitment of CHT-containing vesicles and retrieval of CHT proteins to subcellular organelles. Events that alter the dynamics of either this constitutive or the depolarization-regulated recycling of $\mathrm{CHT}$ will control the amount of choline that is available for ACh synthesis and the ability of cholinergic neurons to communicate with their target cells. It is not known whether the enhanced endocytosis and loss of cell surface CHT proteins in SIN-1-treated cells is a mechanism to remove damaged proteins from the neuron or a protective measure to prevent protein damage, but our previous work examining transferrin receptor disposition in SIN-1-treated cells shows changes to that receptor that parallel effects on CHT (Pinthong et al., 2008), suggesting that this is a more generalized mechanism for the response of some cell surface proteins to cellular stress.

\section{References}

Alkam T, Nitta A, Mizoguchi H, Itoh A, Nabeshima T (2007) A natural scavenger of peroxynitrites, rosmarinic acid, protects against impairment of memory induced by Abeta(25-35). Behav Brain Res 180:139-145.

Apparsundaram S, Ferguson SM, George AL Jr, Blakely RD (2000) Molecular cloning of a human, hemicholinium-3-sensitive choline transporter. Biochem Biophys Res Comm 276:862-867.

Ashki N, Hayes KC, Bao F (2008) The peroxynitrite donor 3-morpholinosydnonimine induces reversible changes in electrophysiological properties of neurons of the guinea-pig spinal cord. Neuroscience 156:107-117.

Beckman JS (1991) The double-edged role of nitric oxide in brain function and superoxide-mediated injury. J Dev Physiol 15:53-59.

Beckman JS (1994) Peroxynitrite versus hydroxyl radical: the role of nitric oxide in superoxide-dependent cerebral injury. Ann N Y Acad Sci 738:69-75

Black SA, Ribeiro FM, Ferguson SS, Rylett RJ (2010) Rapid, transient effects of the protein kinase $\mathrm{C}$ activator phorbol 12-myristate 13-acetate on activity and trafficking of the rat high-affinity choline transporter. Neuroscience 167:765-773.

Bryan-Lluka LJ, Papacostas MH, Paczkowski FA, Wanstall JC (2004) Nitric oxide donors inhibit 5-hydroxytryptamine (5-HT) uptake by the human 5-HT transporter (SERT). Br J Pharmacol 143:63-70.

Chavez JA, Roach WG, Keller SR, Lane WS, Lienhard GE (2008) Inhibition of GLUT4 translocation by Tbcld1, a Rab GTPase-activating protein abundant in skeletal muscle, is partially relieved by AMP-activated protein kinase activation. J Biol Chem 283:9187-9195.

Conner SD, Schmid SL (2003) Regulated portals of entry into the cell. Nature 422:37-44.

Dale LB, Seachrist JL, Babwah AV, Ferguson SS (2004) Regulation of angiotensin II type 1A receptor intracellular retention, degradation, and recycling by Rab5, Rab7, and Rab11 GTPases. J Biol Chem 279:13110-13118.

Damke H, Binns DD, Ueda H, Schmid SL, Baba T (2001) Dynamin GTPase domain mutants block endocytic vesicle formation at morphologically distinct stages. Mol Biol Cell 12:2578-2589.

Dessy C, Kelly RA, Balligand JL, Feron O (2000) Dynamin mediates caveolar sequestration of muscarinic cholinergic receptors and alteration in $\mathrm{NO}$ signaling. EMBO J 19:4272-4280.

Di Stasi AM, Mallozzi C, Macchia G, Petrucci TC, Minetti M (1999) Peroxynitrite induces tyrosine nitration and modulates tyrosine phosphorylation of synaptic proteins. J Neurochem 73:727-735.

Ferguson SM, Blakely RD (2004) The choline transporter resurfaces: new roles for synaptic vesicles? Mol Interv 4:22-37.

Ferguson SM, Savchenko V, Apparsundaram S, Zwick M, Wright J, Heilman CJ, Yi H, Levey AI, Blakely RD (2003) Vesicular localization and activity-dependent trafficking of presynaptic choline transporters. J Neurosci 23:9697-9709.

Fernandes R, Hosoya K, Pereira P (2011) Reactive oxygen species downregulate glucose transport system in retinal endothelial cells. Am J Physiol Cell Physiol 300:C927-C936.

Fischer Y, Thomas J, Sevilla L, Muñoz P, Becker C, Holman G, Kozka IJ, Palacín M, Testar X, Kammermeier H, Zorzano A (1997) Insulininduced recruitment of glucose transporter 4 (GLUT4) and GLUT1 in isolated rat cardiac myocytes. Evidence of the existence of different intracellular GLUT4 vesicle populations. J Biol Chem 272:7085-7092.

Ford MG, Pearse BM, Higgins MK, Vallis Y, Owen DJ, Gibson A, Hopkins CR, Evans PR, McMahon HT (2001) Simultaneous binding of 
PtdIns(4,5)P2 and clathrin by AP180 in the nucleation of clathrin lattices on membranes. Science 291:1051-1055.

Gates J Jr, Ferguson SM, Blakely RD, Apparsundaram S (2004) Regulation of choline transporter surface expression and phosphorylation by protein kinase $\mathrm{C}$ and protein phosphatase 1/2A. J Pharmacol Exp Ther 310:536-545.

Giros B, el Mestikawy S, Bertrand L, Caron MG (1991) Cloning and functional characterization of a cocaine-sensitive dopamine transporter. FEBS Lett 295:149-154.

Guermonprez L, Ducrocq C, Gaudry-Talarmain YM (2001) Inhibition of acetylcholine synthesis and tyrosine nitration induced by peroxynitrite are differentially prevented by antioxidants. Mol Pharmacol 60:838-846.

Haga T, Noda H (1973) Choline uptake systems of rat brain synaptosomes. Biochim Biophys Acta 291:564-575.

Horie T, Ono K, Nagao K, Nishi H, Kinoshita M, Kawamura T, Wada H, Shimatsu A, Kita T, Hasegawa K (2008) Oxidative stress induces GLUT4 translocation by activation of PI3-K/Akt and dual AMPK kinase in cardiac myocytes. J Cell Physiol 215:733-742.

Kaye DM, Wiviott SD, Kobzik L, Kelly RA, Smith TW (1997) S-Nitrosothiols inhibit neuronal norepinephrine transport. Am J Physiol 272:H875-H883.

Li X, De Sarno P, Song L, Beckman JS, Jope RS (1998) Peroxynitrite modulates tyrosine phosphorylation and phosphoinositide signalling in human neuroblastoma SH-SY5Y cells: attenuated effects in human $1321 \mathrm{~N} 1$ astrocytoma cells. Biochem J 331:599-606.

Lorenzen A, Samosh J, Vandewark K, Anborgh PH, Seah C, Magalhaes AC, Cregan SP, Ferguson SS, Pasternak SH (2010) Rapid and direct transport of cell surface APP to the lysosome defines a novel selective pathway. Mol Brain 3:11.

Martín de Llano JJ, Fuertes G, Andreu EJ, Puig O, Chaves FJ, Soutar AK, Armengod ME, Knecht E (2006) A single point mutation in the lowdensity lipoprotein receptor switches the degradation of its mature protein from the proteasome to the lysosome. Int J Biochem Cell Biol 38:1340-1351.

Oh-Hashi K, Maruyama W, Isobe K (2001) Peroxynitrite induces GADD34, 45 , and 153 VIA p38 MAPK in human neuroblastoma SH-SY5Y cells. Free Radic Biol Med 30:213-221.

Okuda T, Haga T (2000) Functional characterization of the human highaffinity choline transporter. FEBS Lett 484:92-97.

Okuda T, Haga T, Kanai Y, Endou H, Ishihara T, Katsura I (2000) Identification and characterization of the high-affinity choline transporter. Nat Neurosci 3:120-125.

Pacher P, Beckman JS, Liaudet L (2007) Nitric oxide and peroxynitrite in health and disease. Physiol Rev 87:315-424.

Park SU, Ferrer JV, Javitch JA, Kuhn DM (2002) Peroxynitrite inactivates the human dopamine transporter by modification of cysteine 342: potential mechanism of neurotoxicity in dopamine neurons. J Neurosci 22:4399-4405.

Pinthong M, Black SA, Ribeiro FM, Pholpramool C, Ferguson SS, Rylett RJ (2008) Activity and subcellular trafficking of the sodium-coupled cho- line transporter $\mathrm{CHT}$ is regulated acutely by peroxynitrite. Mol Pharmacol 73:801-812.

Ramamoorthy S, Bauman AL, Moore KR, Han H, Yang-Feng T, Chang AS, Ganapathy V, Blakely RD (1993) Antidepressant- and cocaine-sensitive human serotonin transporter: molecular cloning, expression, and chromosomal localization. Proc Natl Acad Sci U S A 90:2542-2546.

Ribeiro FM, Alves-Silva J, Volknandt W, Martins-Silva C, Mahmud H, Wilhelm A, Gomez MV, Rylett RJ, Ferguson SS, Prado VF, Prado MA (2003) The hemicholinium-3 sensitive high affinity choline transporter is internalized by clathrin-mediated endocytosis and is present in endosomes and synaptic vesicles. J Neurochem 87:136-146.

Ribeiro FM, Black SA, Cregan SP, Prado VF, Prado MA, Rylett RJ, Ferguson SS (2005) Constitutive high-affinity choline transporter endocytosis is determined by a carboxyl-terminal tail dileucine motif. J Neurochem 94:86-96.

Ribeiro FM, Black SA, Prado VF, Rylett RJ, Ferguson SS, Prado MA (2006) The "ins" and "outs" of the high-affinity choline transporter CHT1. J Neurochem 97:1-12.

Ribeiro FM, Pinthong M, Black SA, Gordon AC, Prado VF, Prado MA, Rylett RJ, Ferguson SS (2007) Regulated recycling and plasma membrane recruitment of the high-affinity choline transporter. Eur J Neurosci 26:3437-3448.

Smith MA, Richey Harris PL, Sayre LM, Beckman JS, Perry G (1997) Widespread peroxynitrite-mediated damage in Alzheimer's disease. J Neurosci 17:2653-2657.

Vanlandingham PA, Ceresa BP (2009) Rab7 regulates late endocytic trafficking downstream of multivesicular body biogenesis and cargo sequestration. J Biol Chem 284:12110-12124.

Wakabayashi K, Nakagawa H, Tamura A, Koshiba S, Hoshijima K, Komada M, Ishikawa T (2007) Intramolecular disulfide bond is a critical check point determining degradative fates of ATP-binding cassette (ABC) transporter ABCG2 protein. J Biol Chem 282:27841-27846.

Wang B, Yang L, Wang Z, Zheng H (2007) Amyolid precursor protein mediates presynaptic localization and activity of the high-affinity choline transporter. Proc Natl Acad Sci U S A 104:14140-14145.

Wang G, Moniri NH, Ozawa K, Stamler JS, Daaka Y (2006) Nitric oxide regulates endocytosis by $S$-nitrosylation of dynamin. Proc Natl Acad Sci U S A 103:1295-1300.

Wang X, Michaelis EK (2010) Selective neuronal vulnerability to oxidative stress in the brain. Front Aging Neurosci 2:12.

Whitehead RE, Ferrer JV, Javitch JA, Justice JB (2001) Reaction of oxidized dopamine with endogenous cysteine residues in the human dopamine transporter. J Neurochem 76:1242-1251.

Xu J, Kim GM, Chen S, Yan P, Ahmed SH, Ku G, Beckman JS, Xu XM, Hsu CY (2001) iNOS and nitrotyrosine expression after spinal cord injury. J Neurotrauma 18:523-532.

Yamamura HI, Snyder SH (1973) High affinity transport of choline into synaptosomes of rat brain. J Neurochem 21:1355-1374. 